\title{
Additional Perspective on Three Balcony Fire Incidents Involving Glass Balustrades
}

\author{
Michael Spearpoint*, OFR Consultants, Manchester, UK \\ Ieuan Rickard, OFR Consultants, Edinburgh, UK \\ Simon Lay, OFR Consultants, Manchester, UK
}

Accepted: 2 July 2021/Published online: 22 July 2021

\section{Dear Editor,}

We have read the recent paper on the 'Qualitative assessment of fire hazard posed by laminated glass balcony balustrades on fire spread' published in Fire Technology by Faudzi et al. [1] with interest. We are also undertaking ongoing work on the topic of the fire performance of laminated glass [2] and part of that study has also been investigating some of the recent incidents in which fires have occurred on balconies with glass balustrades. We would like to offer an additional perspective on three of the incidents discussed by Faudzi et al., namely the West Hampstead square fire (incident \#3) in the Orwell Building, London, UK in 2018, the Lacrosse Docklands fire (incident \#1), Melbourne, Australia, in 2014, and The Lighthouse, Manchester in 2017 (incident \#2). Our findings are based on the design of the existing building prior to the incident, information from the incident itself and any post-incident investigations.

\section{Orwell Building, West Hampstead Square}

Faudzi et al. [1] concluded that the glass used in the balustrades was monolithic. They report that this is based on review of post-fire photographs and also cite a LFB report on the activation of the automatic suppression system present in the building [3]. The LFB report does not describe in detail the type of glass used in the balustrade, only that it was "toughened balustrade glazing". This could mean it was either monolithic or laminated glass since toughened glass panes are typically used in the manufacture of laminated glass for balustrades.

A review of various documentation on the design of the building does not always reveal any information about the glass used in the balcony balustrade. There is no specific information available from the Emporis website [6] or the Bal-

* Correspondence should be addressed to: Michael Spearpoint, E-mail: michael.spearpoint@ofrconsultants.com 
lymore brochure used to sell the flats [7]. However the construction diagrams that are available from Camden Council as part of planning application 2015/5519/P [8] state that the balustrades will be "clear laminate glass".

Several videos of the fire have been published online by the public, Fig. 1. In one video (Fig. 1a) it seems to suggest the inner surface of the glass is burning and also there is burning along the top edge. The 'inner burning' may be the way in which the flames manifest themselves and the edge burning could be the indication of a laminate but also might be adhesive/sealants associated with a capping. However, it is also important to note that another video (Fig. 1b) does show catastrophic glass failure which might suggest monolithic glass, or absence of interlayer at the point of fracture. Watching the videos allows for a much better interpretation of the incident than using still images.

An image taken from a property website in 2019 following the fire suggest that the glass is laminated although it is difficult to claim these images are conclusive. Following this OFR engineers have also been to the building to confirm that the balustrades at present appear to be laminated glass likely with an extruded brushed anodised aluminium or stainless steel capping. In Fig. 2 photographs show there is a laminate layer between the two panes of glass. Overall, we believe there is sufficient evidence to point to the glass being laminated at the time of the incident.

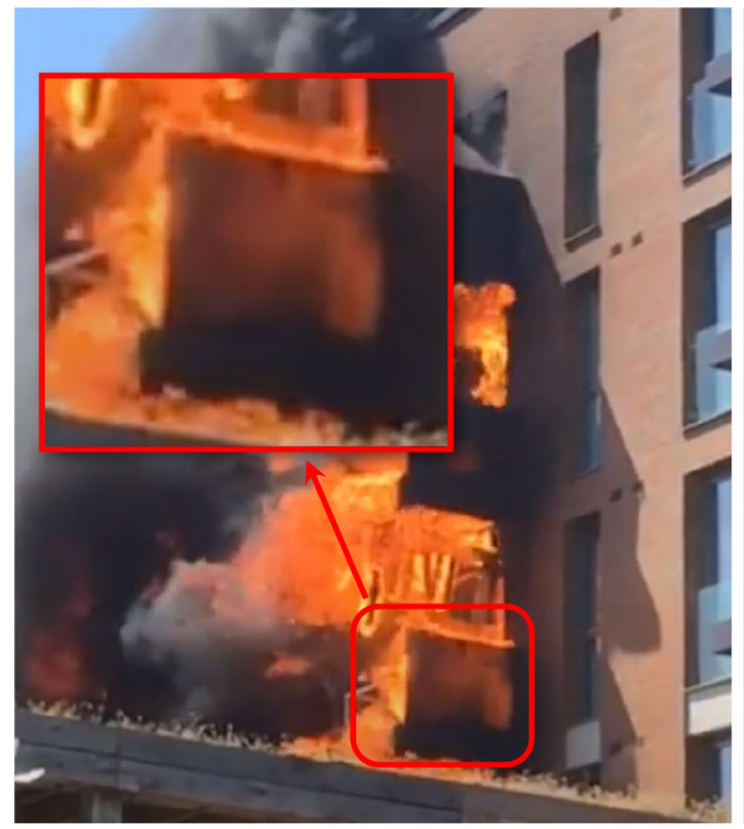

(a)

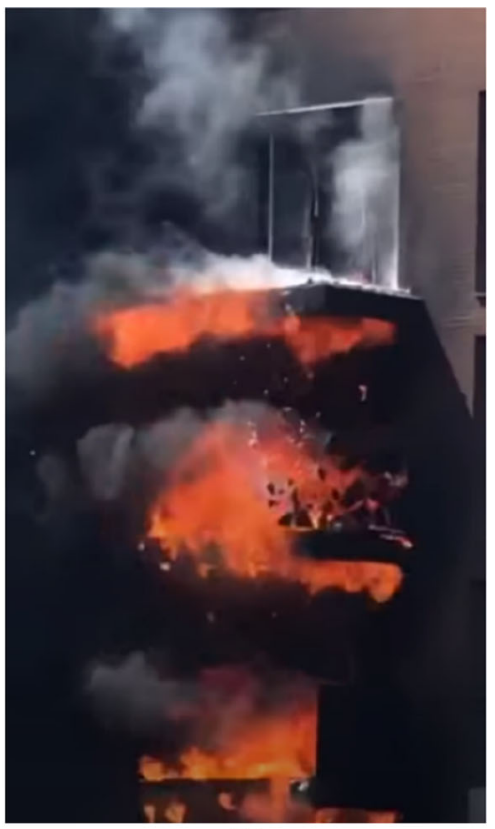

(b)

Figure 1. Images taken from videos posted online (a) Possible flaming of laminate layer [4]); (b) Moment when glass panel shatters [5]. 


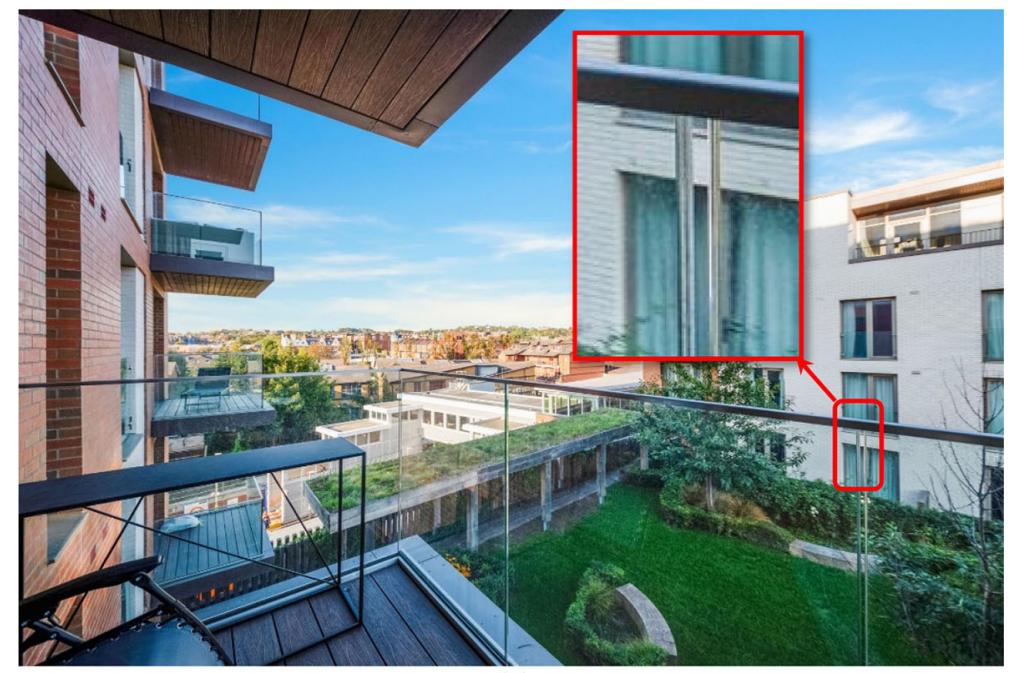

(a)

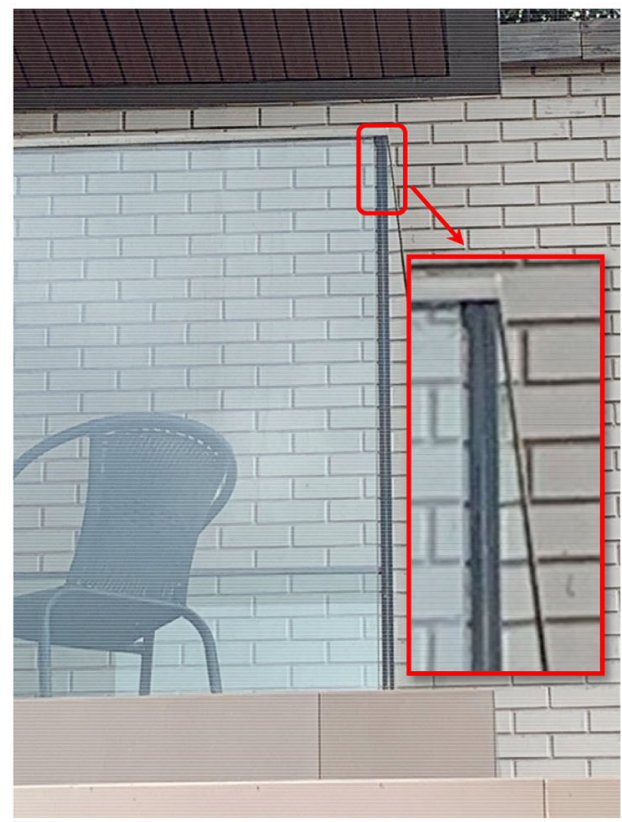

(b)

\section{Figure 2. Class balustrade on the Orwell Building (a) image taken} from a property website [9]; (b) contemporary photograph.

Further to the information presented above, Sapphire Balconies published a report [10] noting that the glass used for the balcony balustrades was laminated. Subsequent discussions by the authors of this letter with Sapphire Balconies 


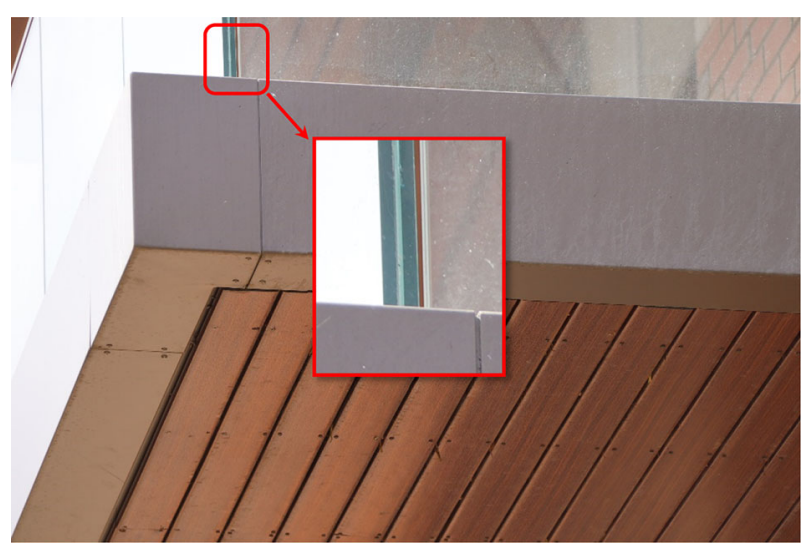

Figure 3. View of the underside of an unaffected balcony on the
Orwell Building at the time of a visit to the scene of the fire (repro-
duced by permission of Nick Haughton, Sapphire Balconies).

revealed a photograph taken at the time a visit to the scene and this is reproduced in Fig. 3.

\section{Lacrosse Docklands}

For the Lacrosse Docklands incident Faudzi et al. deduced the glass was laminated due to the integrity of the glass panes supported by the frame and a "char stain line' resulting from the "... reaction of the organic interlayer with heat".

Identification of the type of glass associated with the balconies on the Lacrosse building in Docklands, Melbourne is challenging. Neither the post-incident reports by the Metropolitan Fire Brigade (MFB) [11] or the city of Melbourne Municipal Building Surveyor [12] give any specific information on the glass used for the balustrade. Similarly, the subsequent tribunal [13] conducted in 2018 does not specifically address the balustrade construction in detail (although it does mention 'laminated glass' but only in the context of what is meant by a laminated product). The authors of this letter have managed to make contact with one of the co-authors of the original MFB investigation, but further details of the glass have not been forthcoming.

Images available from a presentation by $\mathrm{Ng}$ and Smithson [14] show a view of the broken balustrade from the edge which might suggest there is only a single pane of glass (Fig. 4a), but the evidence is unclear. Currently, efforts to contact the authors of the presentation have not been fruitful as they may be able to verify the type of glass or supply a better image.

Attempts to identify the type of glass installed in the balustrade using images from property websites has been limited. The construction of the balustrade does not provide a view of the edge of the glass and none of the available photographs (e.g. Figure 4b) allow for an assessment of the glass thickness which might aid in identifying the glass type. 


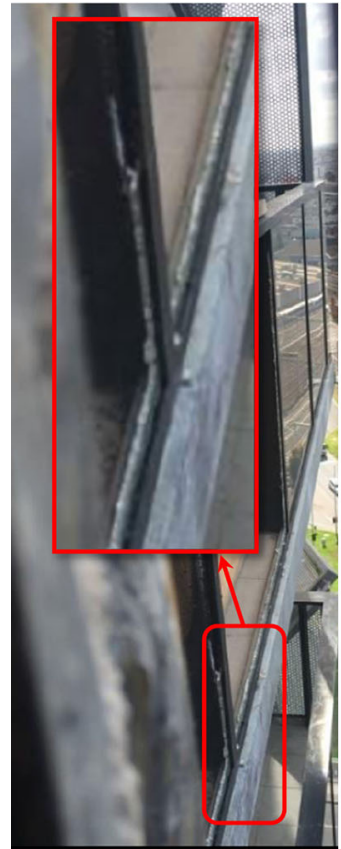

(a)

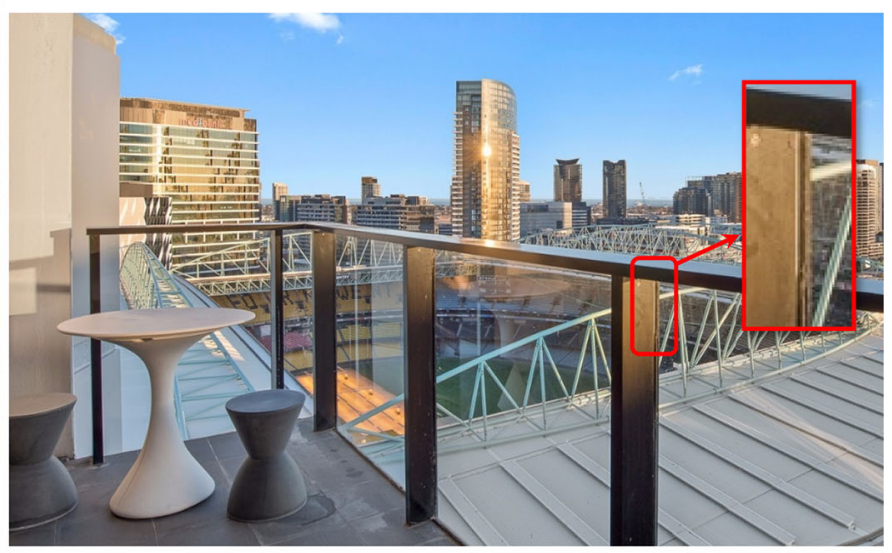

(b)

\section{Figure 4. Lacrosse Docklands balustrade (a) end on photograph after the fire (taken from $\mathrm{Ng}$ and Smithson [1 4]) with expanded inset added; (b) confemporary image [ 15$]$ ]).}

Our investigations have identified who we believe supplied the glass (China Southern Glass Australia Pty Ltd, now ASG International), noting that they apparently supplied both monolithic and laminated glass at the time. Discussions in Australia related to the quality of some imported building materials [16] supports that the glass was supplied by China Southern Glass Australia Pty Ltd by noting that the glass used in the 150 Collins Street building was "...the same product from China Southern used in the Lend Lease Lacrosse Docklands project" although this is not necessarily specific to the balustrades.

What is of interest are the reports in the Australian media [17, 18] from around 2013 that highlight the catastrophic failure of glass balustrades on several balconies across apartments in Melbourne. The failures are thought to have occurred because of nickel sulphide occlusions - a problem that can cause such catastrophic incidents in monolithic glass [19]. One of the press reports notes that one of these incidents occurred in another building that was built by the same developer as the Lacrosse Docklands. It is therefore possible that the developer may have used monolithic glass in other projects, although we recognise this is just conjecture.

The above investigations lead to speculation that monolithic glass was used on the Lacrosse Docklands, although none of this is sufficiently conclusive to rule out laminated glass as a possibility. 


\section{The Lighthouse, Manchester}

In this incident Faudzi et al. concluded the glass was monolithic due to the glass remnants that remained in the balustrade supports and that unaffected glass panes did not exhibit charring or delamination.

From our investigations, there appears to be no readily accessible detail on the design of the balcony balustrade. Information available online from $2 \mathrm{H}$ Architecture [20] who were involved in the conversion of the existing building into the apartment block does not indicate the glass type and an image of the balcony balustrade is not sufficiently detailed for further evaluation. As with the Orwell Building, the Emporis website [21] provides no detailed information other than noting that here the architects are listed as Conran \& Partners.

Videos and photographs taken during the incident are not sufficient to observe how the balustrade performed. We have been in contact with someone who was at Greater Manchester Fire and Rescue Service at the time of the fire, but to date they have not been able to provide further information on the glass type. In addition to those reproduced by Faudzi et al., other post-incident photographs are available which clearly show the damage to the glass (Fig. 5) which suggest that the glass was likely to have been monolithic. In the report from Sapphire [10] they note that "...the monolithic glass smashed".

Images currently available from property websites do not show the balustrade in sufficient detail to make any conclusive assessment and it has not been possible to obtain a contemporary photograph since the building is currently obscured by scaffolding.

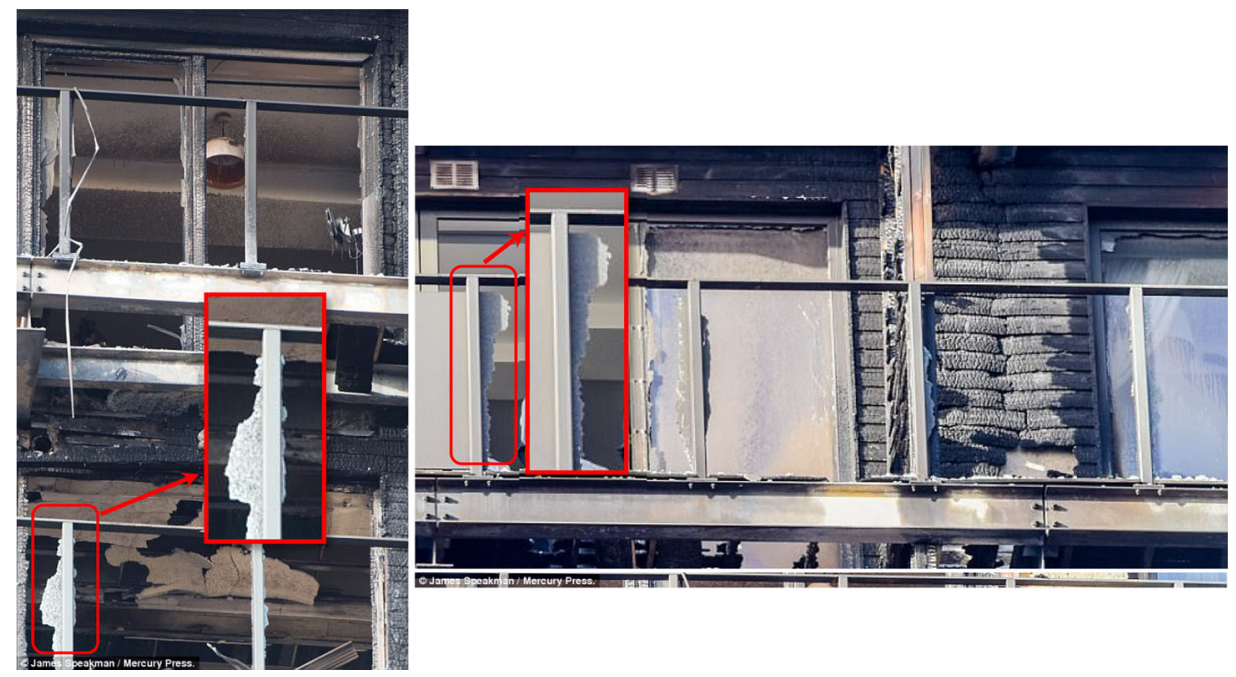

Figure 5. Post-incident images of The Lighthouse fire showing remains of the glass balustrade [22] [Original images cropped, resized and inserts added for clarity]. 


\section{Conclusion}

Based on our findings we would propose that laminated glass was used in the case of the Orwell Building in West Hampstead and tentatively suggest that monolithic glass was used in the balcony balustrades of the Lacrosse Docklands building. These findings are in contrast to the assumptions put forward by Faudzi et al. [1]. We concur that it would appear that monolithic glass was present in the case of The Lighthouse, Manchester incident although relatively little information is available to verify this.

Both the work of Faudzi et al. and our investigations highlight how difficult it can be to definitively identify materials used in the construction of building elements that have been involved in a fire. Ostensibly one might think that all relevant information will be collected at an incident and would be available, particularly after fires of the magnitude of the incidents discussed herein. However, it is possible that either specific information is not recorded at the time as being 'relevant' (since those doing an investigation cannot foresee everything that might be later discussed) or the information has not been released in a public forum (this might be because of legal restrictions etc.). Clearly, care should be taken when trying to characterise materials and in-fire behaviour from photographs and videos.

We would welcome further evidence from other parties who may have more information on the type of glass used in these incidents (or any others). This would ensure that facts are correct, which is important for future decisions that might be made on the safety of laminated glass, both in terms of fire but also the hazards presented should glass fail under normal working conditions.

\section{References}

1. Faudzi Binte Mohd, Schulz J, Dodd G (2021) Qualitative assessment of fire hazard posed by laminated glass balcony balustrades on fire spread. Fire Technol . https:// doi.org/10.1007/s10694-020-01085-8

2. Rickard I, Spearpoint M, Lay S (2020) The performance of laminated glazing subjected to constant heat fluxes related to building fires. Fire Mater 45(2):283-295. https:// doi.org/10.1002/fam.2939

3. London Fire Brigade, 'West Hampstead Square, Automatic Fire Suppression System Activation Case Study', Jan. 2019. www.london-fire.gov.uk/media/5138/westhampstead-square-afss-activation-case-study.pdf

4. M. P. Garcia, 'Fire at the Orwell Building in West Hampstead', youtube.com, Jul. 03, 2018. www.youtube.com/watch?v $=2 \mathrm{j} 8 \mathrm{zk} 19 \mathrm{qW} 3 \mathrm{Y}$ (last accessed Apr. 12, 2021)

5. Camden New Journal, 'Dramatic fire in West Hampstead development', youtube.com, Jul. 03, 2018. www.youtube.com/watch?v = 8gaT-UA50s8 (last accessed Apr. 22, 2021)

6. Emporis, 'Orwell Building', Emporis. www.emporis.com/buildings/1521237/orwellbuilding-london-united-kingdom (last accessed Apr. 10, 2021)

7. Ballymore Group, 'West Hampstead SQ'. Apr. 15, 2014, issuu.com/ballymoregroup/docs/ baly8010_product_brochure_fa_lr (last accessed Apr. 22, 2021) 
8. Camden Council, 'Related Documents-Planning Application No: 2015/5519/P', Camden, 2015. camdocs.camden.gov.uk/HPRMWebDrawer/PlanRec?q = recContainer:\%222015/5519/P\%22 (last accessed Apr. 22, 2021)

9. Rightmove, 'Orwell Building, West Hampstead Square, West Hampstead, London, NW6', Dec. 18, 2019. www.rightmove.co.uk/properties/76253938\#L (last accessed Mar. 29, 2021)

10. N. Haughton, 'Is laminate glass a fire safety risk on balconies', Sapphire Balconies Ltd, May 2020

11. Metropolitan Fire Brigade, 'Post incident analysis report', Melbourne, Australia, Report No: 1403134A, 2014

12. G. Genco, 'Lacrosse Building Fire', City of Melbourne, 8989066, Apr. 2015

13. Owners Corporation No.1 of PS613436T v LU Simon Builders Pty Ltd (Building and Property) [2019] VCAT 286. 2018, p. 227

14. O. Ng and P. Smithson, (2017) 'BG\&E Facade Consultants', presented at the High rise workshop

15. Corporate Keys Australia, 'Corporate Keys - Lacrosse - 2013/675 LaTrobe Street, Docklands, 3008', Corporate Keys Australia, 2013. www.corporatekeysaustralia.com. au/serviced-apartments-docklands/lacrosse/550-lacrosse-2013-675-latrobe-streetdocklands-3008

16. N. Johnson, "Grocon says CFMEU is "ill-informed" after union accuses project of using substandard building product', Architecture \& Design, Jun. 23, 2014.

17. A. Dow, 'Exploding glass balconies in Melbourne apartments expose faulty building products', The Age, Jul. 01, 2017. www.theage.com.au/national/victoria/explodingglass-balconies-in-melbourne-apartments-expose-faulty-building-products-20170628gx0lwf.html (last accessed Nov. 06, 2020)

18. A. Colangelo, 'Glass panel explodes on balcony of luxury inner-Melbourne apartment building', The Age, Jan. 02, 2019. www.theage.com.au/national/victoria/glass-panelexplodes-on-balcony-of-luxury-inner-melbourne-apartment-building-20190102-p50p8v. html (last accessed Nov. 06, 2020)

19. L. Jacob, 'Factors that influence spontaneous failure in thermally treated glass - nickel sulphide', presented at the Glass processing days, Tampere, Finland, Sep. 1997

20. 2H Architecture, 'The lighthouse', 2H Architecture. www.2h-architecture.co.uk/?page_ id $=112$ (last accessed Apr. 22, 2021)

21. Emporis, 'The lighthouse', Emporis. www.emporis.com/buildings/229448/thelighthouse-manchester-united-kingdom (last accessed Apr. 22, 2021)

22. A. Robertson, P. Southworth, and S. Murphy-Bates, 'Devastated remains of Manchester tower block where four floors were destroyed in a blaze spread by wooden balconies', Daily Mail, Dec. 31, 2017. www.dailymail.co.uk/news/article-5224271/ Manchester-fire-spread-wooden-balconies.html (last accessed Apr. 22, 2021)

Publisher's Note Springer Nature remains neutral with regard to jurisdictional claims in published maps and institutional affiliations. 